\title{
Study on the Early-Warning Platform of Dairy Industry Damage in China
}

\author{
Yanfei Bai \\ College of Economics and Management, Beijing University \\ of Agriculture \\ Beijing 102206, P. R. China
}

\author{
Fang Liu \\ College of Economics and Management, Beijing University \\ of Agriculture \\ Beijing 102206, P. R. China \\ livfang@sohu.com
}

\author{
Zhongwei He \\ College of Economics and Management, Beijing University of Agriculture \\ Beijing 102206, P. R. China \\ hzw28@163.com
}

\begin{abstract}
Industrial damage attaches great importance to all countries in the world. It is one of the most important duties of a government to ensure the healthy development of domestic industries. The objective of this study is to achieve informatization of China's dairy industry. Analytic hierarchy process (AHP) and early- warning system were combined to sort, analyze, store and process the indices of dairy products in trade. An early-warning model was used to develop the early-warning platform of dairy damage for real-time tracking of the dynamics development of dairy industry trade and for scientific and accurate determination and prediction of industry losses and damage extents caused by dumping. This practice will effectively protect the interest of the state, and protect China's dairy industry from the infringement of unfair competition.
\end{abstract}

Keywords-Dairy industry; industrial damage; early-warning model; China

\section{FOREWORD}

The Anti-dumping Regulations of the World Trade Organization (WTO) has defined industry damage as the substantial damage, threat or retardation imposed by import goods to the same or similar domestic products that hampered the establishment of the industry. The China Anti-dumping-forcast methods of industry damage extents has defined industry damage as the threat, blocking and destruction brought by large-scale sales of import (export) goods to the development and establishment of domestic industries in international trades. Since China's entry into WTO, the trade of dairy has increased, and the impact of import of foreign products into China has been strengthening. Therefore, to construct an early-warning platform for diary industry damage and to forecast the potential crisis of dairy safety is necessary to minimize the loss and enhance the consumer confidence.

In recent years, some researchers have studied on the construction of early-warning system of industry injury. On the basis of theoretical analysis and practical works, Liu et al. (2001) analyzed the early-warning factors by using analytic hierarchy process (AHP). Following the objective laws of industry injury, the principles of operability, comparability, early-warning, and scientificity, and the statistical indicators of the Bureau of Industry Injury Investigation, Ministry of Commerce of China, Chen et al. (2009) reconstructed a mathematical model to monitor industry damages, which validity and reliability was further confirmed by actual cases. Li et al (2009) established the food security early-warning index system to assess food security status and forecast food security damage, and built a systemic framework with timely policy adjustments. Cheng et al. (2010) constructed an industry safety early-warning system in Henan Province, and performed empirical researches with it. According to the overall goal of food development in China, Shao (2011) analyzed the law of food development in China over years, predicted the future comprehensive alarm limit index of food security by using practical scientific forecast model, and proposed the countermeasure to build food security early-warning system. $\mathrm{Xu}$ et al. (2011) analyzed the security status of aquatic products in Hebei Province, and proposed the basic ideas and frameworks of aquaculture safety warning subsystem. And Zhang et al. (2011) divided the North China area into 14 regions of early warning, and constructed early-warning models of earthquake situation index for each region. The earthquake early-warning criteria were determined, and a regional early warning index system was developed with AHP analysis and earthquake index calculation. Colors red, orange, yellow, and blue were used to grade the earthquake levels.

To guarantee the healthy development of China's dairy industry, this study aims to analyze and construct a dairy industry injury platform in the viewpoints of early-warning system design, model development method, and early-warning platform processes.

\section{INDEX SYSTEM SET-UP OF THE EARLY-WARNING I MODEL OF CHINA'S DAIRY INDUSTRY INJURY}

The dairy industry early-warning indices were designed mainly based on the industrial damage theory and relevant provisions of the state, which were further combined with the dairy industry's own characteristics.

\section{A. Basis for Index System Design}

To select and determine a reasonable index system is the 
key to establish a rapid and accurate early-warning and monitoring system. A set of indicators should have integrity, hierarchy, scientificity and practicality, and feasibility of index data and calculation method. The factors independent from import products must be considered as well.

a) Integrity. Design of industry injury early-warning index system is a systematic engineering. Factors must be considered in combination, such as quantitative calculation and qualitative judgment, comprehensive characterization of index in combination and separately, and static and dynamic analysis of indices. At the same time, the index system design should consider the development and change of the dairy quality security.

b) Hierarchy. The industry injury early-warning index system is composed of a number of indicators with certain functions and mutual connections as a whole, and has hierarchy, in which each index of each level supports and supplements each other. The index system under study is composed of three levels, the low levels reflect the high ones, and the high ones are part of the higher ones.

c) Scientificity and practicality. The objective of establishing an early-warning index system of dairy industry damage in China is to provide a set of practical and comparable assessment basis, which can be used to determine whether China's dairy industry is safe. It's also the basis for implementation of anti-dumping, countervailing, and special safeguard measures. Therefore, index design should have operability. In specific operations, each department can optimize the indicators, highlight the main indices, and improve the evaluation efficiency according to specific need.

\section{B. Index System Design}

To ensure the safety of dairy trade, the early-warning index system should include the indicators of import quantity, import price, industry suffering and some import-independent indicators, according to the principles of decision-making, objectiveness, availability and simplicity. Import quantity index is defined by the change rate of import quantity, import price index by the change rate of price, industry suffering index by the change rate of pre-tax profit, import market share, domestic sale volume, and per capita income. Other import-independent indices are defined by the reduction of domestic consumption demand, the changes of consumption patterns, the effects of trade policy and technological progress, the changes of domestic industry management, the effects of domestic industry competition status, and the effects of irresistible force (Table 1).

TABLE I. THE INDEX SYSTEM OF DAIRY INDUSTRY INJURY EARLY-WARNING MODEL

\begin{tabular}{|c|c|c|c|}
\hline General index & First-level index & Second-level index & Note \\
\hline \multirow{12}{*}{$\begin{array}{l}\text { The indices of dairy } \\
\text { industry injury } \\
\text { early-warning model }\end{array}$} & Import quantity & Change rate of import quantity & Quantitative \\
\hline & Import price & Change rate of import price & Quantitative \\
\hline & \multirow{4}{*}{ Industry suffering } & Change rate of pre-tax profit & Quantitative \\
\hline & & Change rate of import market share & Quantitative \\
\hline & & Change rate of domestic sale volume & Quantitative \\
\hline & & Change rate of per capita income & Quantitative \\
\hline & \multirow{6}{*}{ Import-independent indices } & $\begin{array}{l}\text { Reduction of domestic consumption demand and } \\
\text { changes of consumption patterns }\end{array}$ & Qualitative \\
\hline & & Effects of trade policy & Qualitative \\
\hline & & Effects of technological progress & Qualitative \\
\hline & & Effects of domestic industry management change & Qualitative \\
\hline & & Effects of competition situation of domestic markets & Qualitative \\
\hline & & Effect of irresistible force & Qualitative \\
\hline
\end{tabular}

Among the indices, the change rate of import quantity refers to the increased or decreased ratio of year-by-year imports of dairy products; the basic data were provided by the Customs. The change rate of import price refers to the price ratio of year-by-year import dairy product; the basic data were provided by the Customs. The change rate of pre-tax profit refers to the change amplitude compared to the previous year; the basic data were provided by enterprises. Pre-tax profit, i.e. the total profit, refers to the profit before tax on product income. The formula is as follows: pre-tax profit $=$ sales-selling cost-tax after allocation and addition-fees after allocation. The change rate of import market share refers to the changes in the market share year by year; the basic data were provided by enterprises. The change rate of domestic sale volume refers to the sale changes in dairy products; the basic data were provided by enterprises. The change rate of per capita income refers to the income changes per capita in dairy enterprises; the basic data were provided by enterprises. 
The import-independent index also affects China's dairy products import and export trade; the data were obtained from expert group meetings.

The indicators listed above are the basis of alarm forecast of dairy industry damage. Early-warning forecast is the comprehensive assessment of a variety of indices to monitor the industry status, is the scientific judgment of the industrial operation after comprehensive processing of each monitoring index data, and is to promote the healthy development of the dairy industry finally.

\section{DEVELOPMENT OF EARLY-WARNING MODEL OF CHINA'S DAIRY INDUSTRY DAMAGE}

Industrial damage early-warning is the basis of anti-dumping, the latter is an effective means to resist unfair competition allowed by WTO. The establishment of dairy industry injury early-warning model must therefore comply with the Agreement on Implementation of Article VI of Tariff and Trade1994 of WTO, i.e. Anti-dumping Agreement.

\section{A. Establishment of Monitoring Products}

The principles to determine the key monitoring product catalog, enterprises, and products of cow industry are: products of the current tariff (corresponding to tariff numbers), vulnerable to import and sensitive to import amount, price change, and industry impact, used and consumed in large scales domestically and exported in large amounts. Liquid milk and dried milk products are the main imports of dairy products in China; among them, liquid milk includes milk and yogurt, and dry dairy products include milk powder and whey. China's dairy exports mainly consist of liquid milk (milk and yogurt) and dried milk products (milk powder, dry whey, butter, and cheese).

\section{B. Establishment of Product Monitoring Index System}

The index system includes import/export index, production and management index of domestic dairy processing enterprises, domestic market price and some other unquantifiable factors. The quantitative indicators mainly include the index sensitive to import quantity like the change rate of import quantity, the index of import price, i.e. the change rate of import price, and the indices of industry suffering i.e. the change rates of pre-tax profit, import market share, domestic sale volume change rate, and per capita income. The qualitative indicators include the reduction of domestic consumption demand and the change of consumption patterns, the impact of trade policy, the effect of technological progress, the change of domestic industry management, and irresistible factors. The quantitative analysis was mainly based on the monitoring data of three aspects, including quantity, price and effects on domestic dairy industry. By using the early-warning model, the industry injury early-warning index calculated, and whether the dairy industry was damaged or not was quantitatively assessed. The qualitative analysis was conducted mainly through establishment of hierarchical structure and judgement matrix, and the questionnaires filled by experts with knowledge and experiences. According to the expert questionnaire, relevant limit values were determined, the weight of each factor was calculated, the expert judgement index of dairy industry injury early-warning was predicted, and whether the dairy industry suffered damage was determined.

\section{Establishment of Basic Database}

The data of China's dairy industry injury early-warning platform mainly originated from the Customs, Industry Associations/Bureau of Statistics, dairy processing enterprises, foreign trade associations or consulting companies. These data were input into the industry injury early-warning model through data collection server, and the industry injury early-warning index was calculated automatically (Table 2).

TABLE II. DATA AND ITS SOURCES OF CHINA'S DAIRY INDUSTRY DAMAGE EARLY-WARNING MODEL

\begin{tabular}{|c|c|c|c|}
\hline Groups & Source & Frequency & The contents of data \\
\hline $\begin{array}{l}\text { Import/export } \\
\text { data }\end{array}$ & Customs & Monthly & $\begin{array}{l}\text { Tariff number, quantity, unit price (CIF import, export FOB) / total price, } \\
\text { import/export countryt, trade style, port, destination/source, transportation } \\
\text { mode, and data as detailed as possible }\end{array}$ \\
\hline Industry data & $\begin{array}{l}\text { Associations/ } \\
\text { Bureau of } \\
\text { Statistics }\end{array}$ & Monthly & $\begin{array}{l}\text { Product code, production, total sale amount, domestic sales, average unit } \\
\text { sale price (excluding VAT), final inventory, sales, sale cost, pre-tax profit, } \\
\text { and production capacity (annually) }\end{array}$ \\
\hline \multirow{2}{*}{$\begin{array}{l}\text { Financial data of } \\
\text { enterprise } \\
\text { representatives }\end{array}$} & \multirow{2}{*}{$\begin{array}{l}\text { Dairy } \\
\text { processing } \\
\text { enterprises }\end{array}$} & Annualy & $\begin{array}{l}\text { Product code, production capacity, average number of staff, labor salary, } \\
\text { average investment, and net operating cash flow }\end{array}$ \\
\hline & & Monthly & $\begin{array}{l}\text { Product code, production, domestic sales, average ex-factory price } \\
\text { (excluding VAT), export volume, export price, final inventory, sales, sale } \\
\text { cost, and EBIT }\end{array}$ \\
\hline $\begin{array}{l}\text { Industry data } \\
\text { abroad }\end{array}$ & $\begin{array}{c}\text { Foreign trade } \\
\text { associations } \\
\text { or consulting } \\
\text { companies }\end{array}$ & Annually & $\begin{array}{l}\text { Production capacity, production, trade, import/export price, country, } \\
\text { technology progress, and investment capital etc. }\end{array}$ \\
\hline
\end{tabular}

\section{Construction of Expert Model}

Expert scoring model is to determine the weight of each early-warning index. This process involved in the description of object attributes by experts who conducted evaluation through their understanding of the dairy industry, values and psychological factors. According to the operating status of dairy products monitored and factors of different level, a hierarchical structure and judgement matrix was established. Experts filled in the questionnaire 
on the basis of knowledge and experience. According to the expert questionnaires, relevant limit values were determined, and both quantitative and qualitative indices should be considered in the expert model design. Experts, normally 10-20, must be proficient in this industry, and be representatives of the field. Majors include industrial technology, trade theory and practice, trade and economic law, macroeconomics and taxation, data statistics, comprehensive management, etc.

\section{E. Construction of the Early-warning Model of China's Dairy Industry Damage}

Following the hierarchical principle, to construct an early-warning model of dairy industry injury is a complex multi-attribute decision-making problem. Introduction of the weight can transform the multi-attribute decision-making problem into a single one, which solves the measurement of importance of index attribute values, i.e. the measurement of early-warning index. The monitoring index attributes were also determined. In this study, AHP algorithm was used to determine the weight, 1-9 scale, of the relative importance of various factors in the hierarchy by pair comparison as shown in Table 3 .

TABLE III. MEANINGS OF THE SCALE

\begin{tabular}{|c|c|c|}
\hline $\begin{array}{c}\text { The degree of relative } \\
\text { importance }\end{array}$ & Definition & Note \\
\hline 1 & Equally important & Two equally important targets \\
\hline 3 & Slightly important & Feel one goal is slightly more important than another based on experiences or \\
\hline 5 & Quite important & Feel one goal is more important than another based on experiences or judgment \\
\hline 7 & Obviously important & Feel the imporatnce of a target, and its importance has been proved \\
\hline $2,4,6,8$ & Absolutely important & Feel strongly that a target is more important than another \\
\hline & Intermediate between two & Used when compromise is required \\
\hline
\end{tabular}

\section{1)Establishment of judgment matrix}

By using pair comparison method, the relevant indices of the same level were evaluated. According to the judgment criterion, a judgment matrix was established.

$A=\{$ aij $\}$, in which aij is the Hs criterion, aij=wi/wj. in which wi/wj is the relative importance of $\mathrm{Ai}$ against $\mathrm{Aj}$.

2)Calculation of weights

To calculate the component vector wi of the feature vector w, we used the following formula:

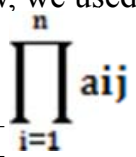

$\mathrm{wi}=[\mathrm{i}=1] 1 / \mathrm{n}$, in which $\mathrm{n}$ is the order of matrix, $\mathrm{i}=1,2, \ldots . \mathrm{n}$

After normalization, the weight of each index was calculated as $\mathrm{WA}=\mathrm{i}=1$ wi . The normalization result of the weight $\mathrm{W}_{\mathrm{i}}$ of $\mathrm{A}_{\mathrm{i}}$ according to Hs criterion is:

$$
\sum_{\mathrm{Wm}=\mathrm{W}_{\mathrm{i}} / \mathrm{W}_{\mathrm{A}}=\mathrm{W}_{\mathrm{i}} / \mathrm{i}=1}^{\mathrm{n}} \text { wi }
$$

For homogeneity check, we used the formula asbelow:
C.I $=\left(y_{\max }-n\right) /(n-1), y_{\max }=\sum_{i=1}^{n}\left(\frac{A W i}{n w i}\right)$, in which C.I. is consistency index. When C.I. $>0.1$, the consistency test failed, a judgment matrix was required to be established; when C.I. $\leq 0.1$, the consistency test worked, namely the judgment matrix was reasonable.

3) Warning process

Calculation of different level indicators was conducted by multiplying the values of each criterion corresponding to the index and weight for linear summation as below:

$$
\sum_{y=1}^{n} x i j w i j \sum_{i=1,2, \ldots m, y_{i m a x}=4}^{n} w i j
$$

The formula of criterion level to target level is:

$$
\sum_{\mathrm{y}=1}^{\mathrm{m}} \text { yiwi } \sum_{\mathrm{i}=1}^{\mathrm{m}} \text { wi } \sum_{\mathrm{j}=1}^{\mathrm{n}} \text { xijwij } \mathrm{y}_{\max }=\sum_{\mathrm{i}=1}^{\mathrm{m}} \text { yimaxwi }
$$

According to $\mathrm{y}_{\max }$, the warning level is divided 4 grades (red, orange, yellow, and blue). Grade red, y (3/4) $\geq y_{\max }$, represents the highest industrial hazard; Grade orange, (2/4) 
$\mathrm{y}_{\max }<\mathrm{y}<(3 / 4) \mathrm{y}_{\max }$, means the higher industrial hazard; Grade yellow, (1/4) $\mathrm{y}_{\max }<\mathrm{y}<(2 / 4) \mathrm{y}_{\max }$, means some unsafe factors; and Grade blue, $\mathrm{y}<(1 / 4) \mathrm{y}_{\max }$, means relative safety.

When set $\mathrm{W}_{\mathrm{i}}$ be the relative importance degree of level $\mathrm{i}$ against the total target level; $D_{i j}$ be the value of index $i$ of level $\mathrm{j}$; and $\mathrm{W}_{\mathrm{ij}}$ be the relative importance degree of index $\mathrm{i}$ of level $\mathrm{j}$ of the index level. According to the principle of AHP, the dairy industry injury early-warning model formula is $\quad=\sum_{i=1}^{m} W_{i} \sum_{i=1}^{n}\left(D_{i j W i j)}\right.$, in which $m$ is the level number, and $\mathrm{n}$ is a specific index number of some index.

\section{THE OPERATION PROCESS OF DAIRY INDUSTRY INJURY EARLY-WARNING PLATFORM}

Local government departments can utilize China's dairy industry injury early-warning system to monitor and audit the data submitted monthly/annually by dairy processing enterprises, the Customs, the dairy industry associations, and foreign institutions. After verification, the data were transmitted to the data collection server. The indices were calculated through the calculation model, and the industry injury early-warning index was determined. At the same time, the expert model assessment index was determined based on the expert questionnaires. The industry injury early-warning index and expert model assessment index were combined to provide a monthly/quarterly/annual industrial damage early-warning report. Suggestions for appeal or response were given to the damaged or seriously damaged industry accordingly. The monthly, quarterly, and annual industrial damage early-warning report was submitted to the National Industrial Damage Early-warning Center. The flowchart is shown in Figure 1:

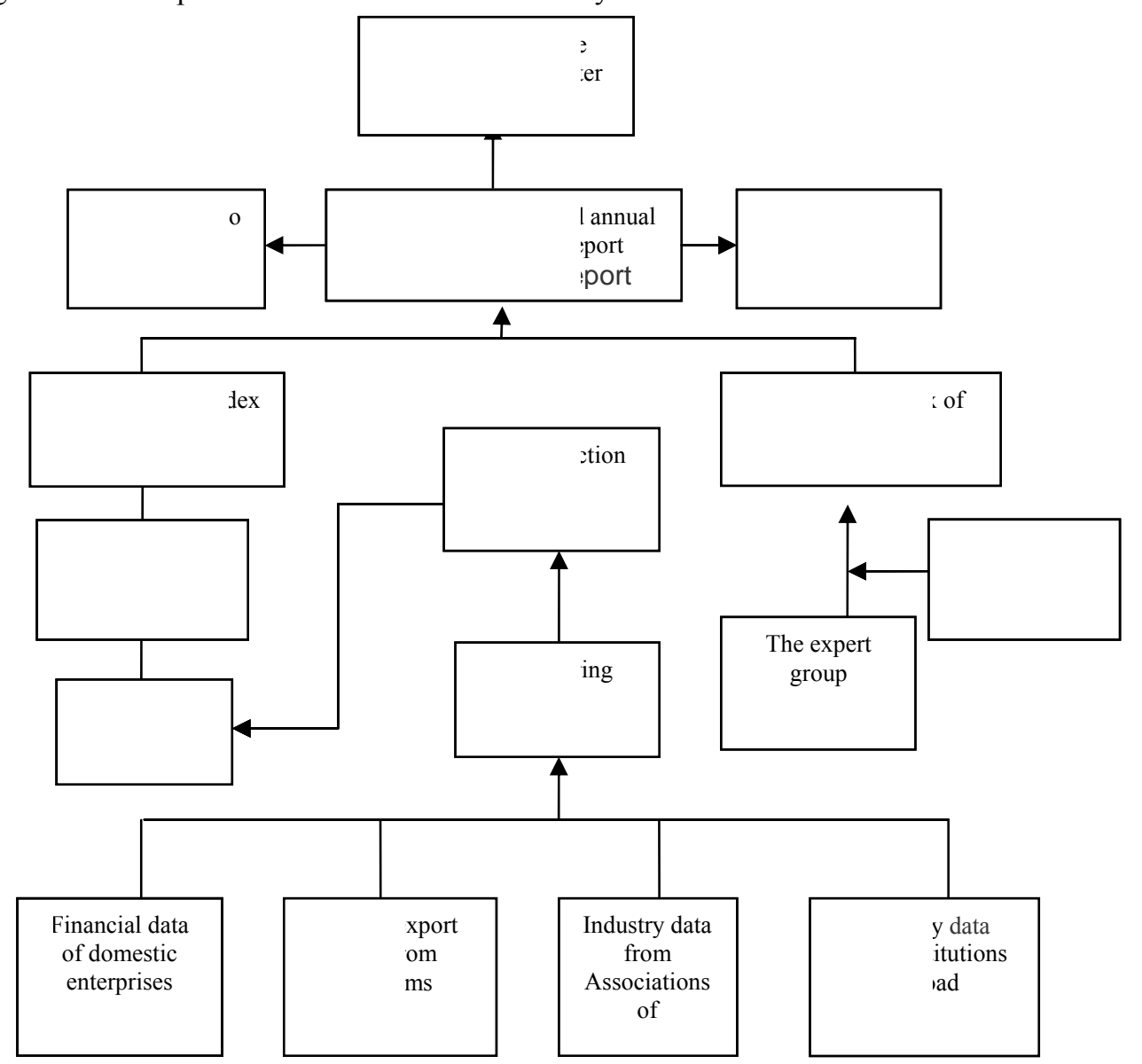

FIGURE 1: THE OPERATION PROCESS OF CHINA'S DAIRY INDUSTRY INJURY EARLY-WARNING PLATFORM

\section{CONCLUSIONS}

Construction of a dairy industry injury early-warning system is one of the most important components of risk and early-warning system of China's macroeconomic policy and has received extensive attention. However, due to the complexity of this problem and the limited nature of human's cognitive ability, the dairy industry damage is a continuous, dynamic, nonlinear, and iterative process. At present, systematic study and analysis is still required in viewpoints of theory, methodology and technology. Therefore, the operational status assessment and monitoring of the dairy industry injury early-warning system require the guidance of scientific theories and methods. Relevant issues still need further in-depth discussion and research. 


\section{ACKNOWLEDGMENT}

Supported by National Natural Science Foundation of China "An Empirical Analysis on the impact of Import Animal Genetic Resources on China's Livestock Economy"

(71073011) and "Study on the early warning system of China dairy industry security" (71373025) "Beijing Innovation Team of Technology System in Dairy Industry" and Program for New Century Excellent Talents in University（NCET-10-009）

\section{REFERENCES}

[1] Youxing Chen, Xu Hui, construction and its fuzzy quantitative evaluation model of industrial damage early-warning, Resources and Industry [J], 2009 (06).
[2] Xu Chunxia, Ceng Zhaochun, construction of aquaculture safety warning subsystem in Hebei Province, China Fishery Economy [J], 2011 (02).

[3] Cheng Jie, the construction of Henan Province food safety monitoring and warning system, Journal of Luoyang Institute of Science and Technology (Social Science Edition) [J], 2010 (02).

[4] Liu Shufeng, Yuan Hailin, analytic hierarchy model of environmental early warning system, Journal of Shaanxi Normal University (Natural Science Edition) [J], 2001

[5] Zhang Shuangfeng, Sun Peiqing, Li Shouyong, research on earthquake pre-warning classification based on AHP method, Earthquake research [J], 2011 (03).

[6] Shao Limin, safety early warning system of grain of our country, management of agricultural economy of [J], 2011 (02). 